\title{
Characterization of $\mathrm{Bi}_{2} \mathrm{Te}_{3}$ thin films grown by pulse electroplating
}

\author{
V. Richoux, S. Diliberto, N. Stein, C. Boulanger \\ Laboratoire de Chimie du Solide Minéral - Electrochimie des Matériaux, \\ Nancy-Université, Université Paul Verlaine-Metz, CNRS, 1 bd Arago, 57078 Metz cedex \\ clotilde.boulanger@univ-metz.fr, virginie.richoux@univ-metz.fr
}

\begin{abstract}
The preparation of bismuth telluride deposits has been performed by galvanostatic pulsed electrolysis from nitric solutions on gold layer deposited on glass. The influence of the chemical conditions and pulsed parameters has been investigated on the stoichiometry and on thermoelectric behaviour for deposited and annealed films. The results demonstrated that improvements of the transport properties in bismuth telluride films can be generated by a pulsed electroplating mode.
\end{abstract}

\section{Introduction}

Bismuth telluride $\left(\mathrm{Bi}_{2} \mathrm{Te}_{3}\right)$ semiconductors and their derivative compounds are considered to be the best materials for use at room temperature [1], in particular $\mathrm{Bi}_{2} \mathrm{Te}_{2.7} \mathrm{Se}_{0.3}$ and $\mathrm{Bi}_{0.5} \mathrm{Sb}_{1.5} \mathrm{Te}_{3}$ for the n-type and p-type respectively. Bulk materials of $\mathrm{Bi}_{2} \mathrm{Te}_{3}$ have been widely integrated in $\mathrm{TE}$ devices used in thermoelectric coolers and power generators. However, $\mathrm{Bi}_{2} \mathrm{Te}_{3}$ thin films promise higher TE efficiency because the TE power of bulk materials can be enhanced through the chaining and stacking of $\mathrm{Bi}_{2} \mathrm{Te}_{3}$ films [2]. As shown by Boikov et al. [3], the lattice thermal conductivity of chalcogenide films is considerably lower than that of bulk crystals of similar compositions, leading to an increase of the figure of merit of films. Furthermore the current tendency towards miniaturization has increased the interest in micro-thermoelectric devices (sensors or generators). Electrochemical deposition (ECD) also opens up opportunities for thin film microsystems since this method is considerably simpler and cheaper than dry processes such as molecular-beam epitaxy, sputtering and metalorganic chemical vapor deposition. Moreover ECD allows growing of uniform films with a thickness ranging from the nanoscale to a few millimeters over large areas, on irregular shaped surfaces and compositionally modulated structures or non-equilibrium alloys. Electrodeposition has been successfully applied to the production of bismuth telluride binaries [4-10] Se-ternary [11], and Sb-ternary [12]. Recently, pulse current plating was investigated $[13,14]$ in order to improve the morphology and properties of bismuth telluride electrodeposits. This process is known to have positive effects on mass transport, electrode kinetics and the nucleation of growth centres. Pulse plating also offers a larger number of parameters (i.e., on-time, off-time, cathodic- and anodic-pulse current density and frequency) than does direct current plating to improve deposit quality $[15,16]$. The present work concerns the characterization of bismuth telluride films synthesized by pulse electroplating. The evolution of roughness as a function of the stoichiometry was studied. Thermoelectric properties (Seebeck coefficient, resistivity) were measured and correlated to the stoichiometry of the films. Finally, the influence of the annealing on the physical properties was studied. All these results were compared to results obtained by direct electrodeposition in order to identify the influence of pulse electroplating.

\section{Experimental}

\section{2-1 Deposition conditions}

Each pulse consists in an "on" time noted $t_{c}$ during which a cathodic current density $\mathrm{I}_{\mathrm{c}}$ (from -60 to $-100 \mathrm{~mA} \mathrm{~cm}^{-2}$ ) is applied followed by an "off" time during which zero current density is applied. The study of the electrodeposition process and deposit preparation was performed in a conventional three-electrode cell using a microcomputer potentiostat - galvanostat Autolab PGSTAT100 with NOVA software. The deposition duration was calculated 
according to the Faraday's law for a targeted thickness of $5 \mu \mathrm{m}$. Reagents used were $\mathrm{Te}^{\circ}$ and $\mathrm{Bi}\left(\mathrm{NO}_{3}\right)_{3}, 5 \mathrm{H}_{2} \mathrm{O}$ dissolved in nitric acid $1 \mathrm{M}$. The tellurite concentration was fixed at $2.10^{-2} \mathrm{M}$ for all mixtures with a $\mathrm{Bi} / \mathrm{Te}$ ratio equal to 2 . The substrate was gold which was deposited by sputtering on glass microscope slides pretreated with an insulating organic coupling agent, (3mercaptopropyl) trimethoxysilane in order to improve gold adhesion [17]. The deposition area was around $1.5 \mathrm{~cm}^{2}$. The substrate was located vertically in a glass cell, whose electrolyte volume was $0.1 \mathrm{dm}^{3}$. Depositions were carried out at room temperature without stirring. The reference electrode was an $\mathrm{Ag} / \mathrm{AgCl}$ electrode and the counter electrode was a graphite bar.

\section{2-2 Deposition characterizations}

Samples were rinsed after electroplating in three steps (nitric acid solution, distilled water and ethanol) followed by drying in air. The roughness was measured with a vertical interferometer (Wyko® NT1100 Optical Profiler). The sample composition was obtained by electron probe microanalysis (CAMECA SX50 and SX100). 5 different measurements were performed and the stoichiometry was determined using the average of these 5 values. In order to measure thermoelectric properties, samples were coated into an epoxy resin (EPOFIX STRUERS) and took off to the substrate. The Seebeck coefficient was measured at room temperature using a Keithley 2700 multimeter. The temperatures of the film were measured using $0.1 \mathrm{~mm}$ diameter $\mathrm{K}$ type standard thermocouples. The voltage was measured between 2 probes held at a fixed distance of $1 \mathrm{~cm}$ from each other. The hot probe was heated to a temperature of $2{ }^{\circ} \mathrm{C}$ above the other one. Electrical resistivity was measured using the 4 point technique, with an HEM-2000 EGK system at a constant current of $1 \mathrm{~mA}$.

\section{Results and discussion}

A previous study showed that it is possible to obtain different film compositions by varying the pulse parameters and the electrolyte composition [14].

According to these results, syntheses were carried out in order to study the influence of the stoichiometry on the transport properties. Experimental conditions used to obtain the different stoichiometries are presented in the table 1. All the films obtained are free of impurities.

Table 1 Experimental conditions applied leading to films with different stoichiometries. $\mathrm{t}_{\text {off }}=1 \mathrm{~s},\left[\mathrm{Te}^{\mathrm{IV}}\right]=2.10^{-2} \mathrm{M}$ in $\mathrm{HNO}_{3}$ $1 \mathrm{M}, \mathrm{Bi} / \mathrm{Te}=2$

\begin{tabular}{c|c|c|c} 
Experimental conditions & $\begin{array}{c}\text { Film } \\
\text { Stoichiometry }\end{array}$ & $\begin{array}{c}\mathrm{At} \% \\
\mathrm{Te}\end{array}$ & $\begin{array}{c}\mathrm{At} \% \\
\mathrm{Bi}\end{array}$ \\
\hline $\mathrm{t}_{\mathrm{c}}=50 \mathrm{~ms}, \mathrm{~J}_{\mathrm{c}}=-60 \mathrm{~mA} \mathrm{~cm}^{-2}$ & $\mathrm{Bi}_{1.97} \mathrm{Te}_{3.03}$ & 60.6 & 39.4 \\
$\mathrm{t}_{\mathrm{c}}=20 \mathrm{~ms}, \mathrm{~J}_{\mathrm{c}}=-60 \mathrm{~mA} \mathrm{~cm}{ }^{-2}$ & $\mathrm{Bi}_{1.93} \mathrm{Te}_{3.07}$ & 61.4 & 38.6 \\
$\mathrm{t}_{\mathrm{c}}=10 \mathrm{~ms}, \mathrm{~J}_{\mathrm{c}}=-100 \mathrm{~mA} \mathrm{~cm}{ }^{-2}$ & $\mathrm{Bi}_{1.91} \mathrm{Te}_{3.09}$ & 61.8 & 38.2 \\
$\mathrm{t}_{\mathrm{c}}=10 \mathrm{~ms}, \mathrm{~J}_{\mathrm{c}}=-80 \mathrm{~mA} \mathrm{~cm}$ & $\mathrm{Bi}_{1.87} \mathrm{Te}_{3.13}$ & 62.6 & 37.4 \\
$\mathrm{t}_{\mathrm{c}}=10 \mathrm{~ms}, \mathrm{~J}_{\mathrm{c}}=-60 \mathrm{~mA} \mathrm{~cm}$ & $\mathrm{Bi}_{1.59} \mathrm{Te}_{3.41}$ & 68.2 & 31.8
\end{tabular}

The roughness of each film has been systematically measured and correlated to the stoichiometry of deposits (figure 1). It can be seen that films having a large excess of tellurium have a smaller roughness than films presenting a small excess of tellurium. These results are comparable to ones observed by Michel et al. [9] for deposits synthesized by continuous electroplating. It confirms that bismuth rich films have a higher surface microstructure, due to a higher crystallization rate. By comparison to films obtained by direct electrodeposition, an improvement is observed. For a same composition, the roughness is divided by 2 when the synthesis is carried out by pulse electrodeposition.

The Seebeck coefficient $\alpha$ and the electrical resistivity $\rho$ of these films were measured and the evolution of these physical parameters as a function of the stoichiometry is presented in the figure 2. All samples exhibit a negative Seebeck coefficient linked to a n-type behaviour. It can be seen that more bismuth rich films have lower Seebeck coefficient values that films presenting a large excess of tellurium. 
Concerning the electrical resistivity, the increase of the tellurium percentage in the films leads to an increase of this parameter. This evolution can be explained by the evolution of the roughness. It has been seen previously (figure 1) that the roughness decreases when the tellurium percentage increases. A smaller roughness is due to smaller grains. Consequently, the films present higher density of grains boundaries which disrupt the circulation of electrons. This statement agrees with our previous work showing the necessity to use high current density in order to obtain small grains.

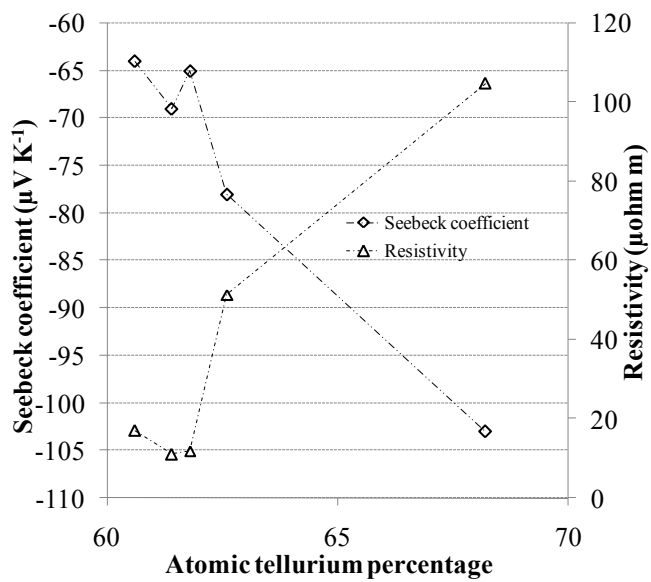

Figure 2 Evolution of the physical properties of films as a function to the tellurium percentage of the deposits. Theoretical thickness $=5 \mu \mathrm{m}$.

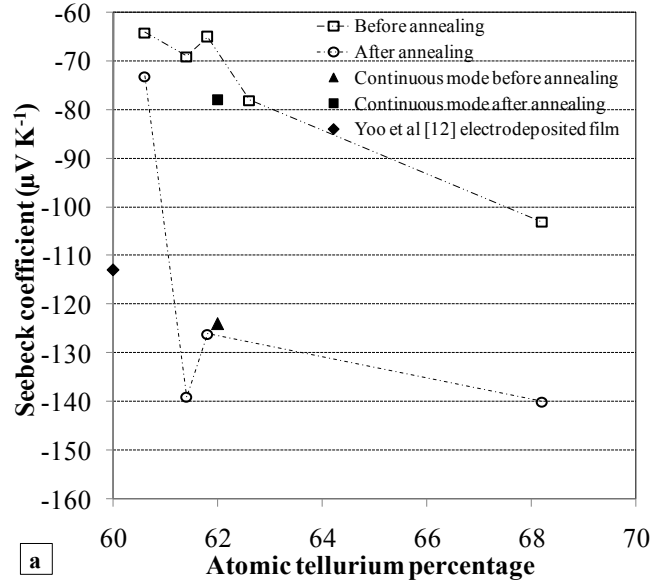

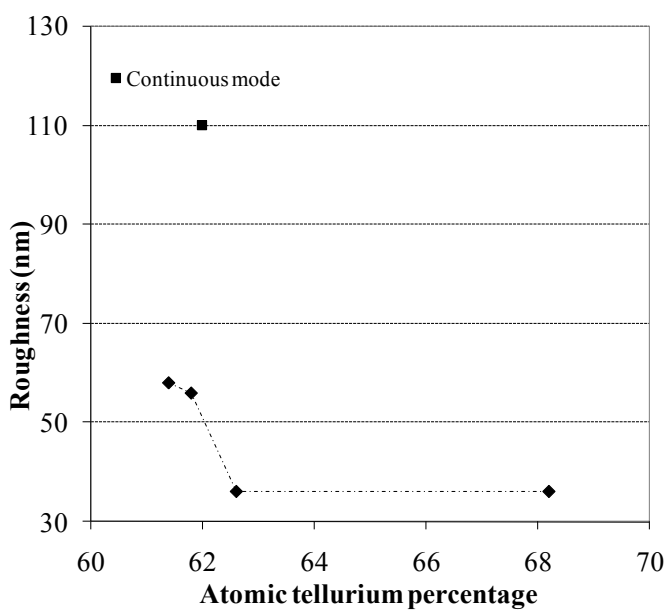

Figure 1 Evolution of the roughness for films presenting different stoichiometries. Theoretical thickness $=5 \mu \mathrm{m}$.

The electroplated films were annealed at $150{ }^{\circ} \mathrm{C}$ during about 15 hours following by a annealing at $300{ }^{\circ} \mathrm{C}$ during 3 hours under inert atmosphere (argon). The aim of this annealing is to improve the physical properties. The evolution of Seebeck coefficient and resistivity as a function of the tellurium percentage is presented in the figure 3. It can be seen that annealing improves clearly the Seebeck coefficient. For example, for a film containing about 61 at $\%$ of tellurium, the Seebeck coefficient

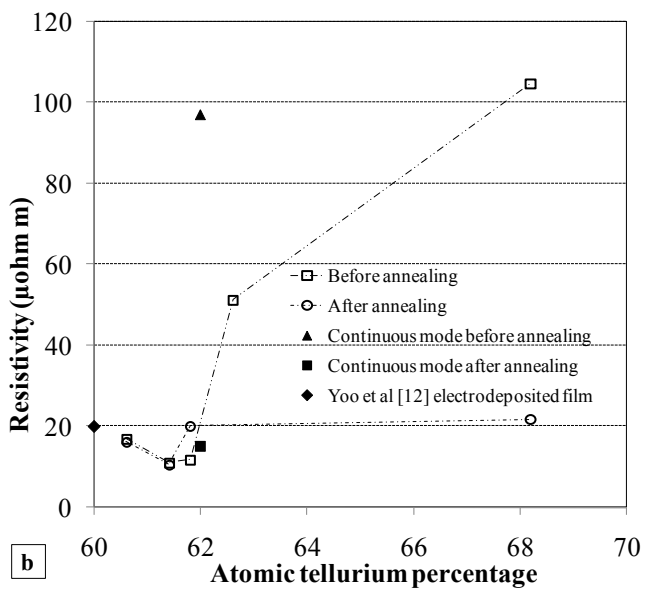

Figure 3 Evolution of the Seebeck coefficient (a) and of the resistivity (b) of pulsed films presenting different tellurium percentages, before and after annealing, compared to values obtained for continuous films.

measured before annealing is about $-70 \mu \mathrm{V} \mathrm{K}^{-1}$ while it reaches a value of $-140 \mu \mathrm{V} \mathrm{K}{ }^{-1}$ after heat treatment. Concerning the resistivity, an improvement can be observed for deposits presenting a large excess of tellurium. For instance, for a film presenting a tellurium percentage about 68 at \%, the resistivity before annealing is about $100 \mu \Omega \mathrm{m}$ and about 20 $\mu \Omega \mathrm{m}$ after heat treatment. However, for films presenting a small excess of tellurium, no improvement is observed after annealing. 


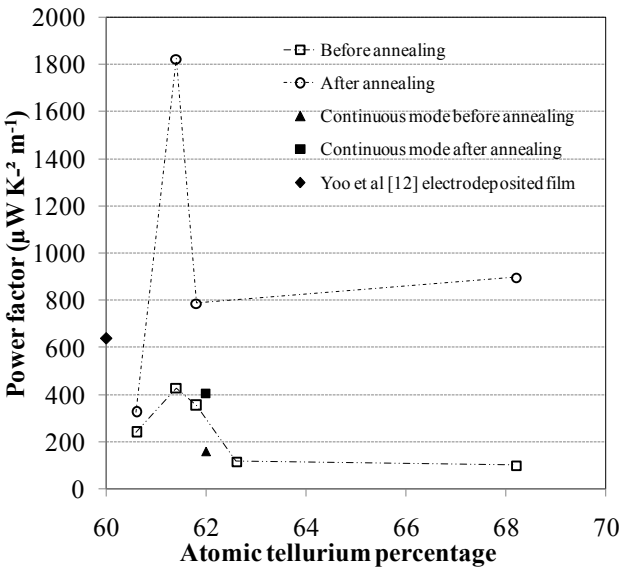

Figure 4 Evolution of the power factor of pulsed films presenting different stoichiometries, before and after annealing, compared to values obtained for continuous films.
The power factor PF $\left(\mathrm{PF}=\alpha^{2} / \rho\right)$ has been calculated for each film before and after annealing have been compared and correlated to the tellurium percentage (figure 4). This graph shows that the power factor has a maximum for a film containing about $62 \%$ of tellurium which corresponds to a stoichiometry closed to $\mathrm{Bi}_{2} \mathrm{Te}_{3}$. Concerning the annealing, a clearly improvement is observed for tellurium rich films due to a high Seebeck coefficient and a small resistivity after heat treatment.

These values have been compared to those obtained for films synthesized by continuous electrodeposition on the same substrate and to values found in the literature.

The use of a pulse electroplating seems to be more promising for tellurium rich films where an improvement of the transport properties is observed.

\section{Conclusion}

Pulse plating has been carried out for synthesis of bismuth telluride films. For a current density equal to $-60 \mathrm{~mA} \mathrm{~cm}^{-2}$, it is possible to adjust the deposit composition. The films have a surface roughness decreased by a factor 2 by comparison to the continuous films showing that the pulsed electrodeposition has an influence on the morphology. The pulsed films presenting a large excess of tellurium have better Seebeck coefficient but a less interesting resistivity than films obtained in direct conditions. Finally a comparison between the values of transport properties obtained before and after annealing was performed. This investigation showed that the heat treatment causes an improvement of the Seebeck coefficient whatever the composition of films. Concerning the resistivity, an improvement after annealing is only observed in the case of pulsed films presenting an excess of tellurium.

1. G.S. Nolas, J. Sharp, H.J. Goldsmid, Thermoelectrics: Basic Principles and New Materials Developments, Ed. Springer, New York (2001)

2. K. Tittes, A. Bund, W. Plieth, A. Bentien, S. Paschen, M. Plötner, H. Gräfe, W. Fischer, J. Sol. State Electrochem., 7, 714 (2003)

3. Y.A. Boikov, B.M. Goltsman, V.A. Kutasov, Sov. Phys. Sol. State, 20, 3002 (1978)

4. M. Takahashi, Y. Katou, K. Nagata, S. Furuta, Thin Solid Films, 70, 240 (1994)

5. P. Magri, C. Boulanger, J.M. Lecuire, Proceedings of the $13^{\text {th }}$ International Conference on Thermoelectricity, Kansas city 1994, in Mathisprakasam and Heenan, AIP Press, New York, 277 (1995)

6. P. Magri, C. Boulanger, J.-M. Lecuire, J. Mater. Chem., 6, 773 (1996)

7. Y. Miyazaki and T. Kajitani, J. Cryst. Growth, 229, 542 (2001)

8. A. L. Prieto, M. S. Sander, M. S. Martin-Gonzalez, R. Gronsky, T. Sands, A. M. Stacy, J. Am. Chem. Soc., 123, $7160(2001)$

9. S. Michel, S. Diliberto, C. Boulanger, N. Stein, J.-M. Lecuire, J. Cryst. Growth, 277, 274 (2005)

10. A. Zimmer, N. Stein, L. Johann, S. Van Gils, H. Terryn, E. Stijns, C. Boulanger, J. Electrochem. Soc., 152, G772 (2005)

11. S. Michel, N. Stein, M. Schneider, C. Boulanger, J.-M. Lecuire, J. Appl. Electrochem., 33, 23 (2003)

12. D. Del Frari, S. Diliberto, N. Stein, C. Boulanger, J.-M. Lecuire, Thin Solid films 483, 44 (2005)

13. D. Del Frari, S. Diliberto, N. Stein, C. Boulanger, J.-M. Lecuire, J. Appl. Electrochem., 36, 449 (2006)

14. V. Richoux, S. Diliberto, C. Boulanger and J.M. Lecuire, Electrochim. Acta 52, 3053 (2007)

15. R.K. Sharma, G. Singh and A.C. Rastogi, Solar Energy Mat and Solar Cells 82, 201 (2004)

16. D. Landolt and A. Marlot, Surf. Coat. Tech. 122, 10 (1999)

17. C.A.Goss, D.H. Charych and M. Majda, Anal. Chem. 63, 85 (1991) 